\title{
A CRITICAL REVIEW
}

\section{SOMATIC RESEARCH IN PERIODIC CATATONIA}

BY

\section{A. B. STOKES}

\section{Introduction}

THE advance of physiological and biochemical knowledge towards the end of the nineteenth century led to an attack upon the problems of general medicine in the chemical field. From this attack the problems of mental disorder were not excluded.

Schaefer, in 1897, reviewed the investigations, which, up to that date, had been made into the metabolism of the insane. Of these narrow and restricted applications of particular tests he said : "It must first be emphasized that they have all one thing in common, namely, that none is concerned with the metabolism as a whole, i.e. with the processes involved in intake and outgo, in the breaking down and building up of the chemical products that constitute the body substance" (Folin's translation).

The publication in 1898 of Kraepelin's nosological concepts applied to dementia præcox gave fresh impetus to the search for a patho-physiological process that might be associated with or held responsible for that condition. Of this work Folin and Shaffer (1904) stated : " the fragmentary nature of all metabolism papers published up to the year 1897 is equally common to those which have appeared since, nor is the accuracy of the experiments or the validity of the conclusions reached any less open to question." They made a plea for carefully planned experiments, for the use of a standard diet, and for the daily investigation over many days or weeks of all the urinary constituents. Such a long-term method took into account the possibility of change of function over a period of time. This principle, which may be called kinetic, they exemplified in their own work and provided a classical example from which they justly concluded that " the data given prove the untrustworthiness of all those metabolism experiments, old and new, which report a 'characteristic' increase or diminution of any of the urinary constituents included in this research (i.e. volume of urine, total nitrogen, urea, ammonia, uric acid, creatinine, organic bases, total sulphates, ethereal sulphates, 'neutral' sulphur, phosphates, chlorides, organic or mineral acids, indican) as associated with any particular one of the ordinary mental disorders. It is not claimed that such characteristic abnormal metabolism may not exist, but simply that the experiments recorded in the literature are insufficient to demonstrate the fact." 
Following Folin's work, Pighini (1906, 1907, 1909, 1910) published his researches on metabolism in dementia præcox. His cases were selected with care, placed on a standard diet, and investigated over a period of time with intent to understand the total aspects of metabolism, e.g. the azotic balance. He also noted the relevance of clinical phase, stating "it was our intention to make a comparison between the metabolism of many cases belonging to several mental disease groups in definite clinical phases" ... (the investigations) " tend to stimulate this method of research, which is by many considered false and without result." Rosenfeld (1906) and Barnes (1909) were others who, each from his own point of view, appreciated the potential value of a broader approach to the problem than that provided by the circumscribed application of particular tests. The work of Barnes is of great value in that it draws attention to the importance of phasic change.

In the subsequent years the relative neglect of this kinetic approach may be attributed to the acceptance of dementia præcox as a disease entity. This acceptance favoured the development of that method of somatic research which might be called the contrasted group method. By this procedure a greater or smaller number of cases conforming to the criteria laid down for the diagnosis of dementia præcox was investigated in respect to particular functions. The findings were then contrasted with those of a normal group or with accepted standard values for normal subjects. The results were disappointing. They were usually negative, and where positive were either not confirmed or contradicted.

It is evident that the success of this method of work, manifest in other branches of medicine, depends on the definiteness of the nosological entity investigated ; but on clinical grounds and perhaps also because of the failure of the organic approach it became more and more apparent that the Kraepelinian system was too rigid. Bleuler in 1911 introduced the term "schizophrenia," which, while it included the dementia præcox cases, had a wider and more elastic scope. The heterogeneity of the schizophrenic group was emphasized by Bleuler himself, who referred to the "schizophrenias" (see Brill's translation, 1915). Campbell in 1928 stated : "the physician interested in the schizophrenic type or reaction finds himself dealing with an extremely largc group of individuals. He has no guarantee that the group of patients is a homogeneous group; he cannot say $a$ priori that the patients are suffering from some unitary disorder." At the same time Meyer (1928), from a point of view which he had long held, discussed the development of the concept of schizophrenia, and commented on the steady progress of a "frank recognition of the pluridimensional character of the facts involved."

This slow shift over many years in clinical position was not reflected in general by a corresponding alteration in the method of metabolic research. Owing to the wealth of clinical material, large numbers of cases were readily available at one time, and tempted investigation along the lines of the contrast group method. Successive reviews, e.g. Bowman (1923), Wuth $(1922,1928)$, indicated the continued return of doubtful or contradictory results, and Page (1934) in connection with carbohydrate metabolism refers to a state of chaos. 
McFarland and Goldstein (1938) were forced to state " it must be confessed, however, that to date the biochemical studies of the psychoses, and particularly those relating to dementia præcox, have done little to lift the fog of confusion and doubt."

The lack of fruitfulness of individual works might be explained by critical reference to such factors as errors of biochemical method and technique, inadequate number of cases studied, or lack of adequate control groups, etc. (e.g. McFarland and Goldstein, 1937), but in general the difficulties and discrepancies have arisen in two ways. First, the schizophrenic cases have been selected without recognition or with but lip service to the recognition of the heterogeneous nature of the schizophrenic group and the operation of definitely exogenous or environmental factors. Secondly, no account has been taken of the very variable course or phasic swings that frequently occur in the physical and mental states of those cases that would reasonably be accepted as endogenous schizophrenic psychoses. Because of the former irrelevant material is introduced, and because of the latter no comparison can be made on the basis of single or relatively few observations. A kinetic method is required and a resort to statistical analysis, so frequently attempted, is not likely to avoid the difficulties.

A consideration of the difficulties implicit in any work on psychosomatic relationships has led Dunbar (1935) to criticize the absence of more work embracing the kinetic principle. In this connection it must be noted that in the period under discussion, although the older kinetic method of approach used by Folin, Pighini, and Barnes had been largely abandoned, its limited use by Rappleye (1919), McCowan and Quastel (1931) led to results which seemed clearer and more hopeful of ultimate value. Moreover, Gjessing since 1926, by the strict application of kinetic principles to the study of metabolic changes occurring in the course of mental disease, has achieved results which call for the closest inspection, but which hitherto have not received the critical attention of writers in English.

\section{Conditions observed}

Gjessing (1932), from the beginning of his work, strictly delimited the conditions under which it was undertaken :

1. From the vast field of the psychoses he selected a very small group of cases which descriptively, in respect of many dramatic qualities, represented a homogeneous selection.

2. Environmental and exogenous factors were excluded with every possible care so that an uncomplicated endogenous metabolism could be studied. Every possible source of sepsis was investigated by every possible means, including instrumentation, X-ray, bacteriological and serological examinations. Positive investigation for sepsis was followed by complete eradication until, after the healing period, the temperature showed a regular daily rhythm and the morphological blood picture remained constant under standard conditions. 
Chronic sepsis is common among the insane (Cotton, 1922, Graves, 1929, Reiter, 1929, etc.), but its removal is carried out by Gjessing without prejudice to the rôle it plays in the causation of mental disorder. That chronic sepsis does influence metabolism (Cramer, 1928) and mental processes (McIntyre, 1927) is a sufficient reason for its eradication in these cases.

Similarly, Gjessing refused, even in the very excited states, the exhibition of drugs in general and hypnotics in particular, because of their influence on metabolism (see Davies and Quastel, 1932).

3. A strict metabolic regime was imposed. A uniform diet of milk, cream, eggs, sugar, and salt, accurately made up, was given in precise quantities. Accessory vitamin factors were added. A nursing staff specially trained and a patient previously " conditioned" ensured the collection of all urine and fæces and a co-operation in technique.

4. The kinetic method was employed. From day to day and week to week serial investigations were carried out along many parallel lines. Well standardized methods of relatively simple technique were selected.

5. Male patients only were examined to avoid the difficulties of the menstrual cycle in females.

The fulfilment of these conditions necessarily indicates the limitations of the method of approach. It must be noted, however, that as far as possible Gjessing has taken into account the factors of homogeneous material and changing phase, and is concerned with the broad aspects of metabolism in relation to the changing phase. He has been prodigal of time and labour on a very few cases and has been content to be patient, not expecting quick returns. In these most important respects his work has offered a marked contrast to other publications.

\section{Clinical material}

The cases under consideration showed, at the time of their investigation, repeated attacks of stupor or excitement and the form of attack manifested by individual patients remained relatively constant. The attacks came on suddenly and disappeared rapidly, while in the intervals the mental state was approximately normal. It is pertinent to consider the clinical diagnosis of these states.

1. In the development of their condition the patients showed earlier attacks, spaced out at intervals of perhaps years, but eventually increasing in frequency with a tendency to regularity. These early attacks were oftentimes overtly schizophrenic with abnormal behaviour, bizarre thinking, and delusions and hallucinations of schizophrenic type.

2. The excited states, over the period of investigation, showed a poverty of ideation, a mechanical automatic kind of excitement with stereotypy, perseveration, and hallucinatory phenomena, which marks them of schizophrenic type.

3. The stupor cases, as described, might conform in some instances to 
Hoch's conception of benign stupors (1921), but in this connection it seems possible that all such deep stupors are of schizophrenic nature (Rachlin, 1937).

4. The intervals of relative normality showed evidence of impairment of mental faculties, indicative of schizophrenia, with lack of volition, poverty of ideation, lack of critical ability, emotional flattening, and mannerisms.

5. Some of the patients described, with a more pyknic type of physical make-up, showed affective lability resembling that of the manic-depressive group, and less evidence of deterioration in the " normal" interval.

Barnes (1909) in an excellent account of two cases descriptively identical with Gjessing's referred to them as "atypical cases related to the dementia præcox group." A similar material has received Kraepelin's consideration (1913). After ascribing such cases to the manic-depressive category, he finally placed them in that subdivision of dementia præcox called periodic catatonia, by so doing emphasizing the differences which exist between them and the pure manic-depressive reaction. Slater (1936), in another connection, has pointed out, as others have done, that a further development of the genetic approach may provide evidence of a fusion of manic-depressive and schizophrenic tendencies in anomalous recurrent illnesses. Until such evidence is forthcoming, Gjessing would appear to be justified in adhering to the name periodic catatonia in the description of his cases.

Kraepelin considered periodic catatonia to be a very small group comprising about 2 per cent. of all cases of dementia præcox. This percentage includes those cases which have not attained to a quick swinging manifestation of mental disorder, and is made up more of females than of males. By his selection, therefore, Gjessing has investigated a relatively rare clinical condition.

\section{Somatic differentiation}

Some of the qualities which unequivocally distinguish periodic catatonia are found less clearly defined and less obviously in other catatonic cases. In these the phasic nature of the mental disturbance is blurred with a gradual transition to stupor or excitement and with a slow emergence from these states. There is no clear interval nor are they ever active mentally in relation to a normal adjustment to their surroundings.

Gjessing has separated these border-line cases from the true periodic catatonia by a consideration of the difference in somatic functional behaviour. In a period of 13 years he has investigated 10 definite periodic catatonics over a total of 3,500 days, and 14 border-line cases over 1,900 days. In the former group, physiological functions change synchronously with the change in mental state, and the total change is a consistent co-ordinated one : thus, in general, one state of vegetative balance gives way to another (e.g. from vagotonia to sympathetotonia). In the latter group the times of change of phase of various functions are not synchronous, and the direction of change is not consistent in terms of vegetative tone. 
The conception of the synchronicity or asynchronicity of change of various functions is easily understood. The conception of a consistent or dissonant change, in terms of vegetative tone, is not so easy to accept. It conforms to the ideas of Eppinger and Hess (1910), and is open to the criticisms to which those ideas have been subjected (see Sachs, 1936). Nevertheless, in the strict periodic catatonic cases, Gjessing has found in definite phases the spread of what might be interpreted as a co-ordinated adrenal sympathetic impulse throughout the organism. This co-ordinated activity in one direction of vegetative balance he calls syntonic, a term which must not be confused with that applied to a type of personality make-up. He therefore contrasts the strict periodic catatonics with their synchronous syntonic mode of reaction (S.-S. type) against the border-line cases with their asynchronous-asyntonic mode of reaction (A.-A. type). The contrast of the somatic functions emphasizes the clinical descriptive contrast, and indicates the definite boundaries of the small group of periodic catatonia outside of which are cases with somewhat similar features but with significant distinctions.

\section{Nitrogen Metabolism}

Disturbances of nitrogen metabolism have been observed in schizophrenia by earlier workers. Pighini (1906, 1907, 1909) and Pighini and Statuti (1910) found a difference in the nitrogen balance of chronic dementia præcox cases and acute catatonic cases. The former retained nitrogen over the period of examination, while the latter excreted it. The two acute catatonics described by Pighini and Statuti were still in a stupor phase, but recovering at the time of negative nitrogen balance. There was also in them an increased output of sulphur in the urine, both absolute and relative to the total nitrogen. The exaggerated elimination of non-oxidized sulphur was regarded as indicating a deficiency in oxidative processes or poisoning. Rosenfeld (1906) found a daily retention of nitrogen in four catatonic patients. They were, however, on a high protein diet and may have suffered from previous inanition. Barnes (1909) investigated two typical cases of periodic catatonia, particularly with regard to nitrogen elimination in the urine. His conclusions were negative, although, as Pighini points out, the estimated nitrogen balance indicates a probable over-excretion at the time of stupor. Kauffmann (1910) wrote in general terms of a disturbance in nitrogen balance in catatonia with an increase of excitement and hyperkinesis after intake of large amounts of protein. Rappleye (1919) found that at the time of entry into catatonic stupor the blood urea showed a distinct fall within a few hours, amounting to 50 per cent. in several cases. He attributed this to a deranged nitrogenous metabolism.

On the other hand, Wuth (1928), who reviewed the earlier work, thought that protein metabolism must be considered normal in an overwhelming majority of cases of schizophrenia, while McFarland and Goldstein (1938), summarizing the blood findings relating to nitrogen metabolism in dementia præcox, were able to set up negative results against the positive results found in individual works. 
In the special group of periodic catatonics (S.-S. type), Gjessing has found a marked phasic disturbance of nitrogen metabolism in which a period of retention is followed by a period of over-excretion and this by a further period of retention and so on. The degree of swing is indicated by a retention and subsequent excretion of about 15-25 grams nitrogen over about 4-8 weeks with individual differences according to the patient. Not only this, but the phasic nitrogen change is associated, in a consistent way, with the phasic mental disturbance. It has been observed that this association is of two kinds. In that type called A type, excitement or stupor sets in just after the time of maximum retention and lasts for the greater part of the period of excretion, while in type $C$ the reactive phase of mental upset (excitement or stupor) sets in just before the time of maximum excretion and lasts for the greater part of the period of retention. Seven cases of A type and 3 of $C$ type have been investigated. Gjessing has reserved the letter $\mathrm{B}$ for a possible intermediate type not yet discovered.

A consideration of the method of establishing these associations is necessary. The mental state is assessed daily in terms of part functions, e.g. mood, motor activity, clarity of consciousness, each of which is awarded a figure on an arbitrary scale of numbers. Thus, in connection with movement, +5 stands for constant movement and 0 for inactivity, without spontaneity, immobility. Such a method is allowable since it is controlled by daily clinical notes and is well adapted for graphic registration. Moreover, the clinical observer is independent of the laboratory worker, so that the mental state assessment remains unbiased by the experimental results, which in any case are returned at a later time. In some instances by the use of an actograph placed under the bed-posts, the onset of the abnormal mental phase (e.g. stupor) can be fixed within a few minutes. The time relationships of the abnormal mental phase and to some degree its extent are therefore adequately observed.

The nitrogen balance curve is drawn up as a consequence of Kjeldahl estimations for total nitrogen on food, fæces, and urine, estimated daily. The food is given in precise quantities and is carefully prepared homogeneous fluid diet, capable of accurate sampling for biochemical analysis. Great care is taken in the collection of urine and fæces, the latter of which is marked weekly by means of charcoal. Loss due to sweat, epithelial debris, seminal excretion, etc., is estimated at $0.3 \mathrm{gms}$. nitrogen a day. This might be considered as low (Peters and Van Slyke, 1931). A correction is also made for incomplete drainage of containers of $0.3 \mathrm{gm}$. nitrogen a day, so that the total correction daily is $0.6 \mathrm{gm}$. added to the negative side. The total correction is probably adequate, since over a period of months the balance curve returns to the same approximate base line. It is to be noted that the frcal nitrogen excretion is low in relation to the total daily excretion, so that the difficulty of placing the fæcal output in its correct time relationship does not seriously alter the time relationships of the total balance curve.

These considerations justify an acceptance of the association of a change in mental state and a change in phase of nitrogen balance occurring in a time sequence under the conditions of the investigation. 
Since environmental and exogenous toxic factors are ruled out, the important outstanding experimental condition to receive notice is that of diet. The total calory value allowed each patient is the basal requirement of an equivalent normal subject plus 25 per cent. On this basis, Gjessing's curves of body weight remain surprisingly constant and any weight lost in the active phase of mental disorder (about 2 kilograms) is rapidly made up later. The weight of a patient aged 14 shows a steady increase. This calory allowance must therefore be considered as adequate. The total nitrogen allowance comes out at about 10-12 gm. a day. This is lower than the average taken in the course of everyday life by normal men, but is well above the minimal protein requirements where the total calories are adequate (Hutchinson and Mottram, 1936), and is of high biological value. Again the constancy of the weight curves confirms the sufficiency of the allowance.

Accessory vitamins are given in addition to those plentifully present in the uncooked diet, and clinically the state of nutrition is well maintained.

In a consideration of the $\mathrm{A}$ type of association of mental phase and nitrogen balance as given above, it might be thought as obvious that with the onset of an excited reactive phase there would be a negative nitrogen balance, secondary to the excitement and its muscular over-activity, particularly if there was any tendency to under-nutrition during the excitement. The extra calory requirements of the excitement would then have to be made up at the expense of body substance. Even when the reactive phase is one of stupor, with a patient immobile, almost akinetic, Gjessing has shown that there is an increased oxygen consumption. This increased metabolism might require the using up of body tissue with an increased output of nitrogen. However, the diet is presumed adequate, since the body weight falls so little in the active phase of mental disorder. Furthermore, in studying the time sequence, the reactive phase, whether of excitement or stupor, sets in just after increased excretion of nitrogen has started.

If the question as to whether the nitrogen changes are secondary or not is equivocal when type $\mathrm{A}$ is considered, the matter is made almost beyond doubt by a study of $C$ type. Here the reactive phase, whether of excitement or stupor, occurs at the time of nitrogen retention, and this retention is taking place despite a slight fall in body weight. It can therefore be said that the disturbance of nitrogen metabolism is not secondary to the nutritive or muscular state occurring in the reactive phase. Such a conclusion is only warranted if the $A$ type and $C$ type cases represent the same essential disorder. Apart from the changes in nitrogen metabolism, they are almost identical both clinically and in respect of somatic functions.

Interpretation of the phasic nitrogen balance must also be considered from the point of view of absorption from the gut. Disregard of this factor possibly accounts for some of the conflicting interpretations of glucose tolerance tests in the psychoses. In Gjessing's figures, however, it may be seen that the fæcal nitrogen remains relatively constant throughout the period of investigation and that the relative balance curves calculated from food and 
urine alone follow the real balance curves very closely. The factor of faulty absorption thus can be excluded as not significant in explanation.

The conclusion appears warranted that the phasic disturbance of nitrogen metabolism is fundamental and is not a secondary derivative of the mental state. Moreover, since in the individual case, the mental disorder sets in consistently at the same time in relation to the nitrogen balance phase, it would appear that the mental disorder is secondary to the nitrogen disturbance or to some factor that at the same time determines the swings in the nitrogen balance curve.

The following facts have reference to a decision between these alternative hypotheses :

1. The mere fact of placing a patient on a standard diet with relatively constant protein intake induces a regularity in the attacks of stupor or excitement.

2. In an individual case, the protein intake is in inverse proportion to the length of the period of nitrogen swing, and within limits regulation of the protein intake adjusts the quiescent interval. Thus, when protein intake is diminished, the quiescent interval becomes prolonged ; when increased, the interval period is shortened.

This important relationship would appear to require much more investigation, since it is so crucial for the discussion of the dependence of mental state on nitrogen metabolism.

3. Gjessing has used large doses of thyroxin to deplete the body's nitrogen store by $60 \mathrm{grm}$. or more. At the lower level of depôt nitrogen (maintained by continued thyroid dosage), the phasic nitrogen swings flatten out and the mental state remains free from its periodic upset.

4. The use of a milk and vegetable diet of low protein content appears to be an important factor in preventing the reaccumulation of nitrogen to the body's nitrogen depôt, after depletion has been brought about by thyroxin and the reduction maintained by a continued exhibition of thyroid. This preventive action on storage is attended by a freedom from mental symptoms.

That such modifications in mental state can be produced by intervention in the nitrogen metabolism is strong support for the conclusion that the mental disorder follows directly upon a disturbance of nitrogen metabolism.

Gjessing has speculated on the nature and mechanism of the nitrogen retention. His studies on the nitrogenous substances in the blood indicate that the nitrogen does not accumulate there, and that thus there must be a tissue retention. He conceives the retained nitrogen as being added to the total depôt nitrogen (Boothby, Sandiford, etc., 1925), and suggests the liver as a possible organ of storage. In this connection it may be noted that the quantity of nitrogen involved in the phasic retention is surprisingly constant for the individual patients, although differing in different patients.

Scheid (1937), in an investigation of febrile episodes in schizophrenic psychosis, has found evidence of hæmolysis occurring at these times. He suggests that the negative nitrogen balance occurring in Gjessing's cases may 
be due to the breaking down of hæmoglobin and the positive balance due to its reformation. His cases were not particularly of the periodic catatonic group and the operation of toxic exogenous factors may be suspected, despite the effort made to exclude these. In any case it would appear difficult to accept this explanation, particularly when retention is occurring in the active phase of mental disorder, as in the $\mathrm{C}$ type above.

In Gjessing's first paper, while considering S.-S. stupor, he showed that the urinary excretion of inorganic sulphur and inorganic phosphate followed with slight deviations that of the nitrogen excretion. The sulphur curve coincided more nearly with that of nitrogen, and he was inclined to believe that the nitrogen changes were bound with those of sulphur and phosphorus. In his later papers he reported results tending to contraindicate this.

The fate of the retained nitrogen must be regarded at the moment as speculative. Gjessing's working hypothesis is that at the time of change of phase in a varying nitrogen balance, a toxic substance, connected with disturbances of protein metabolism, is produced which acts in an inhibitive or irritant way on the central nervous system. He suggests that this substance may be an amine or a protein breakdown product of unknown or atypical kind. This idea has been put forward by previous writers on very much less evidence (Pighini and Statuti, 1910 ; Barnes, 1909 ; Looney, 1924 ; Reid, 1927 ; etc.), and invites a comparison with the work on experimental catatonia in animals (De Jong, 1931, and Baruk, 1933), the effects of mescalin in the production of schizophrenic symptoms in humans (Guttmann and Maclay, 1936), and the inhibitory effect of amines on the oxidation of glucose in brain tissue (Quastel and Wheatley, 1933).

\section{Vegetative-Endocrine disturbances}

At the time of change from quiescent interval to reactive phase (whether of stupor or excitement, in both $\mathrm{A}$ and $\mathrm{C}$ types) disturbances occur which, in general, may be regarded as of vegetative origin. Gjessing interprets them as indicating an adrenal-sympathetic impulse spreading relatively suddenly over the vegetative field, and giving the impression of an irritant reaction. He thus summarizes these disturbances under the term irritation symptom-complex. The hypothetical irritant is the presumed product of anomalous protein metabolism and its place of action possibly the vegetative centres of the diencephalon.

There are many well observed facts on which this working hypothesis is based.

1. At the time of onset of stupor or excitement the patients show pallor, cold and clammy extremities, mydriasis; the pulse rate is increased and the blood pressure rises ; a rise of temperature is recorded. Other workers have described similar changes, and Barnes (1909) particularly has published curves indicating strikingly similar findings in two cases, clinically conforming to Gjessing's group. Scheid (1937) has, from a different angle, investigated particularly febrile episodes in schizophrenia. The temperatures he has found are much higher than 
those of Gjessing's, and the question of a significant infective element or drug intoxication cannot be ruled out as readily. The care with which Gjessing's data have been collected establishes the facts beyond question.

2. As the reactive phase of mental disorder progresses, the vegetative changes become less marked and more stabilized, although in type $\mathrm{C}$ there is greater lability than in type A. Towards the end of the reactive phase and with recurrence of the "quiet" interval, conditions revert to their former state.

3. At the time of onset of stupor or excitement there is an increase of oxygen consumption with an increase of basal metabolic rate. Later in the reactive phase this is lessened, and sinks to its previous value in the quiescent phase.

Basal metabolic studies in the psychoses can always be criticized, owing to the difficulties of ensuring the patients' co-operation. Gjessing in his later studies uses a Knippings apparatus with a head mask and always insisted on a long preliminary training of his subjects. Oxygen consumption was measured over two consecutive periods and the procedure repeated unless there was fair accord.

Other workers have found changes in basal metabolism in groups of schizophrenics (Bowman, 1928 ; Lingjaerde, 1932 ; Hoskins, 1937), although these have been accounted insignificant by others (Northcote, 1932). Gjessing's investigations were carried out every two days, and their value lies not so much in the accuracy of the individual test as in the consistently repeated serial change which they demonstrate.

4. The reactive phase of mental disorder is ushered in by a rise in the fasting blood sugar level and the blood sugar tolerance curve increases in height. These findings are stated as the result of sugar tolerance tests carried out at different points not of the same swing but of different swings in their phasic sequence. The similarity, almost identity, of successive swings as seen in the other findings justifies this method.

The enumerated changes conform in type to those found by Cannon (1929), and interpreted by him as of sympathetic origin. It might be thought that they represented the somatic expression of emotional disturbances occurring in the patients at the times of onset of their illnesses (cf. Bard, 1929). The fact that they have been observed to occur during sleep, at the onset of the illness, does not offset this completely. On the other hand, the changes may be representative of some of the features observed in relation to the specific dynamic action of protein and may thus be linked up with the disturbances in nitrogen metabolism. The work of Freeman (cited by Hoskins, 1937) is of interest in this connection, if stomach irritation can be excluded. The giving of amino-acetic acid by mouth was attended by an increase of oxygen consumption, rectal temperature, and the rate of insensible perspiration. Again the facts may be interpreted as a response to a toxic substance (see Cramer, 1928), possibly a derivative of protein metabolism. The question must therefore remain open, in view of these very general analogies, as to whether the 
vegetative findings are a consequence of the mental state or a more direct result of the disturbances in nitrogen metabolism.

Interesting changes synchronous with the onset of the reactive mental phase have been found by Gjessing in the blood. There is a definite rise of total leucocytes with an increase of polymorph percentage ; the sedimentation rate diminishes. Changes in leucocyte count have been frequently reported in schizophrenia (Dide and Chenais, 1902 ; Bruce and Peebles, 1904 ; Barnes, 1909 ; Heilemann, 1910 ; and Scheid, 1937). The elucidation of the significance of relatively slight changes in this field is fraught with difficulty, owing to the known errors due to technique and the normal variations. Again, it is the consistency of Gjessing's findings from period to period, in the absence of all sepsis, that gives his observations positive value. The explanation of the findings must be speculative, but it is possible that they occur in relation to the change of vegetative state or as a response to the presence of the hypothetical protein toxic substance.

Gjessing has pointed out, in connection with his stupor cases (A type), that certain features can be picked out suggesting a disturbed thyroid function. In the " normal " interval there is torpidity, with a dull, inactive skin, associated with a low basal metabolic rate while in the later stages of stupor there is protrusis bulbi, increased pulse rate, tremor, increased susceptibility to oxygen deprivation, and a slightly raised basal metabolic rate. Interesting in this respect are the changes found in the electrocardiogram. During the quiescent interval, when nitrogen is being retained, and the clinical picture resembles that of subthyroidism, there is a completely flat $T_{1}$; at the beginning of overexcretion $T_{1}$ is exaggerated, but returns to normal in a few days. These changes are comparable to those found in experimental catatonia by Baruk and Racine (1938). Gjessing points out that the same characteristics are found in mild anoxæmia and myxœdema.

However, in the $\mathrm{C}$ type cases the same electrocardiographic abnormalities occur, again during the phase of nitrogen retention, but now with the patient in his reactive state, with increased pulse rate, oxygen consumption, etc. At that time relative hypothyroidism cannot be presumed, nor is an increasingly negative value of the impedance angle, reported in that phase, sufficient to support the hypothesis. The explanation of these facts must await further development. It must be emphasized, however, that Gjessing's suggestion of a phasic thyroid dysfunction occurring in his cases was not the determinant of his method of treatment.

\section{Compensation of Nitrogen Metabolism}

Gjessing (1938, 1939) has described his method of " compensating" the functional nitrogen disturbances in periodic catatonia (S.-S. group) by the use of thyroxin and thyroid. Other workers have used thyroid in the treatment of schizophrenia, e.g. Leeper (1900), Minski (1927), Lingjaerde (1932), Sargent, Fraser and Brazier (1938), and they appear to have been concerned chiefly with counteracting a presumed thyroid hypofunction. On the other hand, 
removal of part of the thyroid has been considered effective (Berkley and Follis, 1908). In the work under discussion, thyroxin has been used to deplete the body's nitrogen store (compare Ross, 1913), and thyroid given as a maintenance dose to conserve that depletion. Tomasson (1938) states he has used ephedrine with success. The thyroxin dosage is high (40-50 mgm. over 8-10 days) and the nitrogen lost to the body considerable, with marked loss of body weight. Subsequently, under thyroid, the body weight again rises, although the nitrogen store remains low. The tolerance to thyroid and a gain in weight under its exhibition have been observed by others (e.g. Lingjaerde, 1932 ; Sargent, Fraser, and Brazier, 1938), but Gjessing's findings are referable only to the small group of cases he has carefully chosen. In them his method of treatment has been successful in the sense of compensating a functional upset, similar to the use of insulin in diabetes. By this compensation his patients have been rendered symptom-free for years. In the light of the insistence on the clear indications for therapy as to clinical type and somatic function, the treatment should not be confused with that more haphazard thyroid therapy which, in general, has fallen into disrepute.

\section{Other functional disturbances}

The quickly recurring manifestations of mental upset have also lent themselves, in Gjessing's hands, to a study of acid base equilibrium : water balance and creatine-creatinine metabolism. The results have appeared to him to be outside the main issue of his problems. Together they have been called a secondary interference symptom-complex and seem to be related both to the phase of nitrogen balance and to the phase of mental upset. At the present time they are difficult to understand clearly and to explain fully.

\section{Conclusion}

The work under review has been concerned with a very small, carefully selected group of patients, conveniently called periodic catatonic. The somatic functions of these cases have been investigated under definite conditions by the use of kinetic methods of investigation. The responses in these circumstances have been factually stated, as the result of meticulous investigations, by Gjessing, and stand out clearly without equivocation. The small number of cases does not offset the value of the work, since large numbers of periods have been examined with remarkably constant results. Interpretation of the facts necessarily involves a consideration of the specific conditions under which they were educed. Taking them into account, Gjessing's conclusion that there is a fundamental disturbance of nitrogen metabolism appears justified, and indicates a specific form of therapy.

A fruitful work invariably points to other problems which await solution. In the present instance there are many. Would any members of the normal population show such a swinging nitrogen metabolism under standard conditions? The almost insuperable difficulty of similarly investigating normal 
controls must be accounted a disadvantage in this work. However, the significant contrast at the moment is not so much between normal cases and periodic catatonics as between reactive phase and quiescent interval in the periodic excursion, and between " uncompensated" and "compensated" cases.

What is the relationship between the greater group of endogenous schizophrenics with marked catatonic features and this group : what are the factors which differentiate the A.-A. type of response from the S.-S. type ? Gjessing is inclined to relate the A.-A. type of response to asthenic habitus and pluriglandular deficiencies, partly of constitutional nature and perhaps also conditioned by long-standing sepsis in early years. This notion is very highly speculative, but the specific chemical attributes of the asthenic constitution have been stressed in the work of Jahn (1938).

Do similar changes occur in the manic-depressive group ? Gjessing has not investigated a pure manic-depressive case. Pighini (1910) investigated the nitrogen balance of one manic depressive case without finding a disturbance in negative or positive direction. Folin and Shaffer (1904) found an increased output of phosphorus in the urine on the "bad" days of a two-day cycle manic-depressive who at post mortem was found to have general paresis. Cuneo (1914-1915) found a retention of nitrogen in the manic phases of the manic-depressive psychosis.

Is there a correlation with other cyclic changes? Similar investigations are still required to be carried out on women who are recognized as showing more frequently the clinical state of periodic catatonia ; more or less remote association with menstruation may be suspected (Compare Horwitz and Harris, 1936).

Is there a rhythmic endocrine disturbance more fundamental than the periodic nitrogen swings? Richter (1927) has produced cyclical changes of activity in animals by interference with the endocrine elements and has discussed his results in relation to the manic-depressive psychoses (Richter, 1938). Endocrine researches point to the effect of the pituitary on protein metabolism, e.g. Schaffer and Lee (1934) have shown that in normal rats the anterior pituitary growth hormone stimulates protein anabolism. Gjessing was able, in one of his cases, to produce a compensation of the disturbance in nitrogen metabolism by using thyreotropic hormone in place of thyroxin.

Is there a genetic basis for these cyclical metabolic phenomena ? Some of Gjessing's cases show a loaded family history, occasionally including periodic catatonia itself.

More intrinsic to the investigations themselves is the problem of the relationship between the A type and $\mathrm{C}$ type and that of the intermediary products of the nitrogen metabolism with their possible toxic action. The hypothesis of such toxic action is difficult, although not impossible, to apply in like manner to both $\mathrm{A}$ and $\mathrm{C}$ type, since the nitrogen balance is proceeding in a different direction during the mental disorder of these two types.

Whatever questions remain unanswered, Gjessing, by his painstaking and detailed work in an isolated small field of the vast territory of endogenous schizophrenia, has pointed to somatic disturbances which seem to play a 
primary rôle in the causation of the mental disturbances occurring there. Such a work is of tremendous importance in the pathology of schizophrenia.

\section{REFERENCES}

Bard, P. (1929). The Foundations of Experimental Psychology. Clark University Press, Section 12, 449.

Barnes, F. M. (1909). Amer. J. Insan., 65, 559 and 591.

Baruk, H. (1933). Encéphale, 28, 645.

Baruk, H., and Racine, M. (1937). Rev. Neurol., 68, 853.

Berkley, H. J., and Follis, R. H. (1908). Amer. J. Insan., 65, 415.

Bleuler, E. (1911). Aschaffenburg's Handbuch der Psychiatrie, 4, Leipzig and Vienna.

- (1924). Textbook of Psychiatry, 373. English Edition, Allen and Unwin.

Boothby, W. M., Sandiford, I., Sandiford, K., and Slosse, J. (1925). Trans. Assoc. Amer. Phys., 40, 195.

Bowman, K. M. (1923). Amer. J. Psychiat., 2, 379.

(1928). Assoc. Res. nerv. ment. Dis., Section in Schizophrenia, 262, Hoeber, N.Y.

Bruce, L. C., and Peebles, A. S. M. (1904). J. ment. Sci., 50, 409.

Campbell, C. M. (1928). Assoc. Res. nerv. ment. Dis., Section in Schizophrenia, 16. Hoeber, N.Y.

Cannon, W. B. (1929). The Bodily Changes in Pain, Hunger, Fear, and Rage. Appleton, 2nd Edition.

Cotton, H. A. (1922). Amer. J. Psychiat., 2, 157.

Cramer, W. (1928). Fever, Heat Regulation, Climate and the Thyroid Adrenal Apparatus. Longmans Green, London.

Cuneo, G. (1914). Riv. sper. Freniat., 40. Reviewed (1915). Riv. Patol. nerv. ment., 20, 190.

Davies, D. R., and Quastel, J. H. (1932). Biochem. J., 26, 1,672.

De Jong, H. (1931). Nervenarzt., 4, 65.

Dide, M., and Chenais, L. (1902). Ann. méd. Psychol., 16, 404.

Dunbar, H. F. (1935). Emotions and Bodily Changes. New York.

Eppinger, H., and Hess, L. (1910). Die Vagotonie. Berlin.

Folin, O., and Schaffer, P. (1904). Amer. J. Insan., 60, 699.

- (1905). Ibid., 61, 299.

Freeman, H. (1937). Cited by Hoskins.

Gjessing, R. (1927). Norsk Mag. Laegevidensk., 88, 832.

- (1932a). Arch. Psychiat., 96, 319.

- $(1932 b)$. Ibid., 96, 393.

- (1932c). 5th Congr. Scand. Psychiat.

(1935). Arch. Psychiat., 104, 355.

-_ (1938). J. ment. Sci., 84, 608.

(1939). Arch. Psychiat., 109, 525.

Graves, T. C. (1929). J. ment. Sci., 75, 31.

Guttmann, E., and Maclay, W. S. (1936). J. Neurol. Psychopath., 16, 193.

Heilemann (1910). Allg. Z. Psychiat., 67, 414.

Hoch, A. (1921). Benign Stupors. Macmillan and Co., N.Y.

Horwitz, W. A., and Harris, M. M. (1936). Amer. J. Psychiat., 92, 1403.

Hoskins, R. G. (1937). Arch. Neurol. Psychiat., Chicago, 38, 1,261.

Hutchinson, R., and Mottram, V. H. (1936). Food and the Principles of Dietetics. Arnold, London.

Jahn, D. (1938). Nervenarzt, 11, 500.

Kauffman, M. (1910). Pathologie des Stoffwechsels bei Psychosen, Jena. Part 3, 218.

Kraepelin, E. (1899). Neurol Zbl., 18, 91.

- (1913). Psychiatrie, 3, 806.

Leeper, R. R. (1900). Brit. med. J., 1, 194.

Lingjaerde, O. (1932). 5th Congr. Scand. Psychiat.

Looney, J. M. (1924). Amer. J. Psychiat., 4, 29.

McCowan, P. K., and Quastel, J. H. (1931). Lancet., 2, 731.

McFarland, R. A., and Goldstein, H. (1937). Amer. J. Psychiat., 93, 1,073.

- (1938). Ibid., 95, 509.

McIntyre, H. D. (1928). Ibid., 7, 919.

Meyer, A. (1928). Assoc. Res. nerv. ment. Dis. Section in Schizophrenia, 5, 3. Hoeber, N.Y.

Minski, L. (1927). J. ment. Sci., 73, 414.

Northcote, M. L. M. (1932). Ibid., 78, 263.

Page, I. H. (1934). Section in The Problem of Mental Disorder. McGraw Hill, N.Y.

Peters, J. P., and Van Slyke, D. D. (1931). Quantitative Clinical Chemistry, 270. Baillière, Tindall and Cox, London. 
Pighini, G. (1906). Riv. sper. Freniat., 32, 355.

(1907). Ibid., 33, 566.

Pighini, G., and Statuti, G. (1910). Amer. J. Insan., 67, 299.

Quastel, J.H., and Wheatley, A. H. M. (1933). Biochem. J., 27, 1,609.

Rachlin, H. L. (1937). Psychiat. Quart., 11, 436.

Rappleye, W. C. (1919). J. nerv. ment. Dis., 49, 130.

Reid, B. (1927). J. ment. Sci., 73, 254.

Reiter, P. J. (1929). Zur Pathologie der Dementia Pracox. Køpenhavn.

Richter, C. P. (1927). Quart. Rev. Biol., 2, 307.

- (1938). Arch. Neurol. Psychiat., Chicago, 39, 587.

Rosenfeld, M. (1906). Allg. Z. Psychiat., 63, 367.

Ross, E. L. (1913). Arch. int. Med., 12, 746. (1914). Ibid., 13, 889.

Sachs, W. (1926). The Vegetative Nervous System. London.

Sargent, W., Fraser, R., Brazier, M. A. B. (1938). J. ment. Sci., 84, 255.

'Schaefer, A. (1897). Mschr. Psychiat. Neurol., 11, 157, 229, 377, 443.

Schaffer, N. K., and Lee, M. O. (1934). J. biol. Chem., 108, 355.

Scheid, K. F. (1937). Febrile Episodem bei Schizophrenen Psychosen. Leipzig.

Slater, E. (1936). Proc. roy. Soc. Med., 29, 39.

Tomasson, H. (1935). 6th Congr. Scand. Psychiat.

Wuth, O. (1922). Untersuchungen über die Körperlichen Storungen bei Geisteskranken. Springer, Berlin.

(1928). Section in Bumke's Handbuch der Geisteskranken. Berlin. 